\title{
Changing patterns of thyroid cancer in different stages of Universal Salt lodization in Peking Union Medical College Hospital, 1986-2018
}

\author{
Ziyang Zeng ${ }^{1 \#}$, Kang $\mathrm{Li}^{2 \#}$, Weiming Kang ${ }^{1}$, Jianchun $\mathbf{Y u}^{1}$, Xianze Wang ${ }^{1}$, Zimu Zhang ${ }^{1}$, Juan Sun ${ }^{1}$, \\ Siwen Ouyang ${ }^{1}$
}

${ }^{1}$ Department of General Surgery, ${ }^{2}$ Department of Vascular Surgery, Peking Union Medical College Hospital, Chinese Academy of Medical Sciences and Peking Union Medical College, Beijing, China

Contributions: (I) Conception and design: W Kang, J Yu; (II) Administrative support: None; (III) Provision of study materials or patients: Z Zeng, K Li; (IV) Collection and assembly of data: J Sun, S Ouyang; (V) Data analysis and interpretation: X Wang, Z Zhang; (VI) Manuscript writing: All authors; (VII) Final approval of manuscript: All authors.

\#These authors contributed equally to this work.

Correspondence to: Weiming Kang. Department of General Surgery, Peking Union Medical College Hospital, Chinese Academy of Medical Sciences and Peking Union Medical College, No.1 Shuaifuyuan Wangfujing Dongcheng District, Beijing 100730, China. Email: kangweiming@163.com.

Backgrounds: Iodine intake may be associated with increased thyroid cancer, but its effect varied from places to places. Universal salt iodization (USI) has been introduced in China from 1996 to 2012. The effects of increased iodine intake on thyroid cancer needs to be investigated in China.

Methods: From 1986 to 2018, patients who had thyroidectomies in Peking Union Medical College Hospital (PUMCH) were retrospectively studied. The detection rate, constituent ratio, mean age, sex distribution of thyroid cancer and the pattern of papillary thyroid microcarcinoma (PTMC) were compared between different historical periods.

Results: The detection rate of thyroid cancer in thyroid surgery significantly increased from $6.77 \%$ to $75.78 \%$ post-USI, with papillary thyroid cancer (PTC) being the majority, and that of follicular thyroid cancer (FTC) and medullary thyroid cancer (MTC) showed only minor changes. There was a descending trend of female/male ratio in PTC from 3.7 to 2.8, and a slight decrease of mean age observed in PTC after USI compared with during USI. The percentage of PTMC in PTC decreased from $13.99 \%$ to 8.64\%, with a lower mean age after USI $(44.88 \pm 10.37$ vs. $46.44 \pm 10.42)$. Prevalence of goiter coexisting with PTMC was also lower after USI than during USI (31\% vs. 41\%).

Conclusions: With the popularization of iodized salt, PTC has become the major type in surgery for thyroid cancer, and trends in other histological subtypes remained mostly stable over the periods. The increase in PTC cannot be attributed to the increase of PTMC which is smaller than $1 \mathrm{~cm}$, indicating that contributing factors other than diagnostic activities, may play a role in the increase of PTC.

Keywords: Papillary thyroid cancer (PTC); thyroid cancer; papillary thyroid microcarcinoma (PTMC); universal salt iodization (USI)

Submitted Mar 12, 2020. Accepted for publication Aug 13, 2020.

doi: $10.21037 / \mathrm{gs}-20-346$

View this article at: http://dx.doi.org/10.21037/gs-20-346

\section{Introduction}

Thyroid cancer has been one of the rapidly growing malignancy in the past 20 years and is estimated to be the $4^{\text {th }}$ most common cancer in 2030 globally (1). Thyroid cancer is the $7^{\text {th }}$ most common cancer in China (2) and the incidence rate of thyroid cancer has increased to 
$9.61 / 10^{5}$ (3). Apart from some of the known risk factors of thyroid cancer, such as radiation exposure $(4)$, obesity $(5,6)$, population ageing (7) and so on, excessive iodine intake is suspected to be yet another contributing factor for thyroid cancer $(8,9)$. Iodized salt has been introduced in many countries to control iodine deficiency disorders, including goiter, infant anomalies and cognitive impairments (10). In the similar purpose of correcting severe iodine deficiency disorders, China also started the national programme of universal salt iodization (USI) in 1996. While the iodized salt programme worldwide greatly improved endemic diseases such as goiter and cretinism, there were elevations in the incidence rates of thyroid cancer in many countries (11-14). One study showed that the incidence rate of thyroid cancer raised from $1.13 / 10^{5}$ (in 1995) to $6.36 / 10^{5}$ (in 2010) in Beijing, a northern city and the capital of China (15). In another study in Shanghai, the incidence rate of men and women raised from $1 / 10^{5}$ and $2.6 / 10^{5}$ to $3 / 10^{5}$ and $11.6 / 10^{5}$ between 1983 and 2007, respectively (16). In 2012, to modulate iodine intake to a more appropriate level, the implementation of USI changed from "universal" to iodineaddition according to regional iodine level. It is thus of importance to investigate the status of thyroid cancer after more than a decade's implementation of USI, and after a moderate iodization of salt was re-introduced in recent years.

In Peking Union Medical College Hospital (PUMCH), a leading tertiary medical center in Beijing and China, we compared between the patterns of thyroid cancer in different stages of USI over a 33 -year period, covering the period before USI (1986 to 1996), during the implementation of USI (1997 to 2012) and a shift to moderate salt iodization (2013 to 2018), to investigate the possible effect of USI exerted on the pattern of thyroid cancer. We present the following article in accordance with the STROBE reporting checklist (available at http://dx.doi. org/10.21037/gs-20-346).

\section{Methods}

\section{Data}

Records of thyroidectomies between 1986 and 2018 were obtained from a medical record database in PUMCH and a total of 34,213 cases of thyroidectomy were extracted. The study was conducted in accordance with the Declaration of Helsinki (as revised in 2013) and approved by the Ethics Committees of Peking Union Medical College Hospital
(No. S-K1336). Because all the parameters were routinely obtained at the time of the study and no additional investigations or procedures were carried out, informed consent was not required. The WHO international classification of thyroid cancer (TC) was used. A total of 614 cases were excluded because of surgery for cancer recurrence $(\mathrm{n}=528)$ and uncertain diagnosis between benign or malignant tumors $(n=86)$. Then the study focused on the major categories of TC: papillary thyroid cancer (PTC) $(\mathrm{n}=17,505)$, follicular thyroid cancer (FTC) $(\mathrm{n}=149)$ and medullary thyroid cancer (MTC) $(\mathrm{n}=152)$. Undifferentiated thyroid cancer $(n=3)$, because of its rarity in thyroidectomy, did not undergo further investigation. In addition, papillary thyroid microcarcinoma (PTMC) were listed as a single category of histological type in the data since 2009, which distinguished it from non-micro-PTC, so the data of PTMC were analyzed between 2009 and 2018. As a result, 17,806 cases of PTC, FTC or MTC were divided into three historical periods: the period between 1986 to 1996 (before the implementation of USI): 149 cases; 1997 to 2012 (during the implementation of USI): 3,990 cases; and 2013 to 2018 (modulation of salt iodization): 13,667 cases.

\section{Statistical analysis}

Statistical analysis was performed with the statistics software SPSS (ver. 20.0; SPSS Inc., Chicago, IL, USA). Data were analyzed with the Student's $t$-test for normal distributed variables, and the chi-square test for nonparametric data. Numerical data were presented as mean \pm SD, where appropriate. A P value below 0.05 was considered statistically significant. Bonferroni corrections were applied (0.05 divided by 3 , which is the number of comparisons between three historical periods; significantly different at a $\mathrm{P}$ value below 0.017 ), where appropriate.

\section{Results}

\section{The detection rates of thyroid cancer in three historical periods}

A total of 17,806 cases of thyroid cancer (TC) were detected in 33,596 cases of thyroidectomies. The detection rate of TC during USI was significantly higher than that of TC before USI $\left(29.87 \%\right.$ vs. $\left.6.77 \%, \chi^{2}=585.43, \mathrm{P}<0.001\right)$. And the detection rate of TC after USI was significantly higher than during USI (75.78\% vs. $\left.29.87 \%, \chi^{2}=6,574.38, \mathrm{P}<0.001\right)$. Particularly, it can be observed that a distinct and continuous 

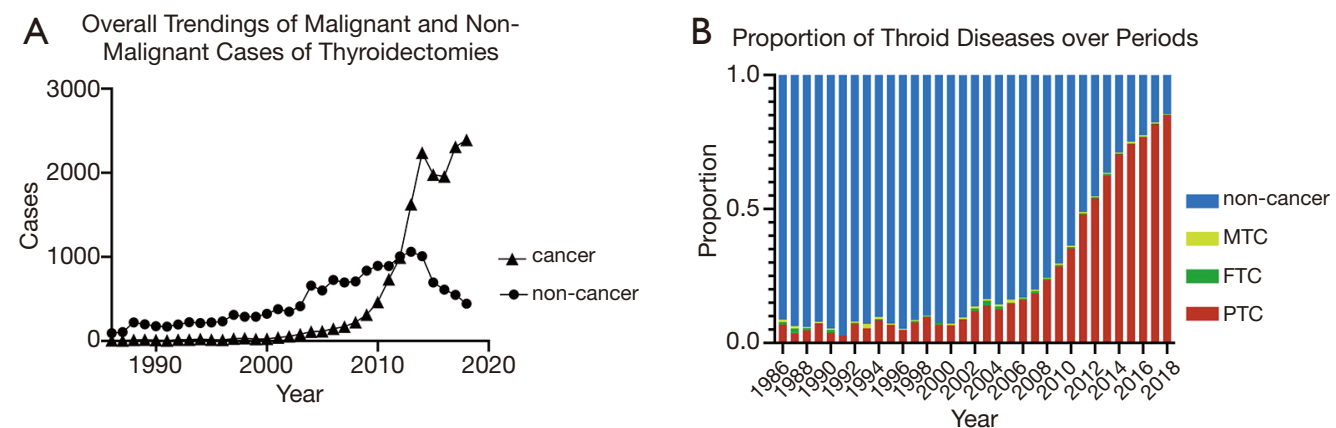

Figure 1 The changing pattern of thyroid diseases over a 33-year span. (A) Cases of malignant thyroid disease showed a drastic increasing trend, while the benign cases gradually increased then decreased. (B) The proportion of the malignant cases rapidly increased and gradually outweighed the benign cases.

Table 1 Time trend of the detection rate of PTC, FTC and MTC in all thyroidectomy

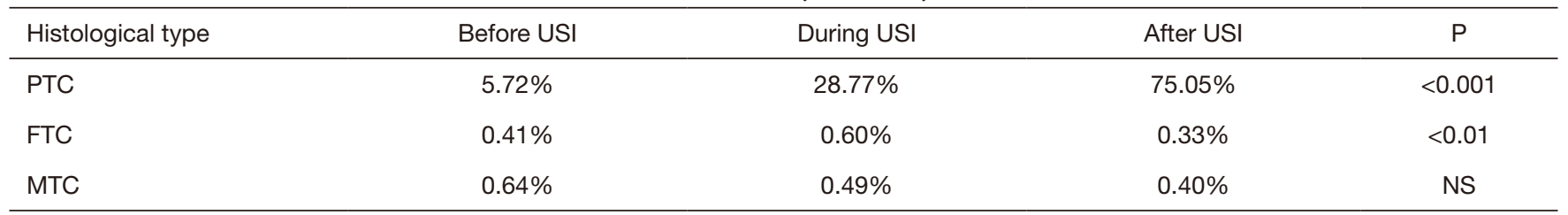

PTC, papillary thyroid cancer; FTC, follicular thyroid cancer; MTC, medullary thyroid cancer; USI, universal salt iodization.

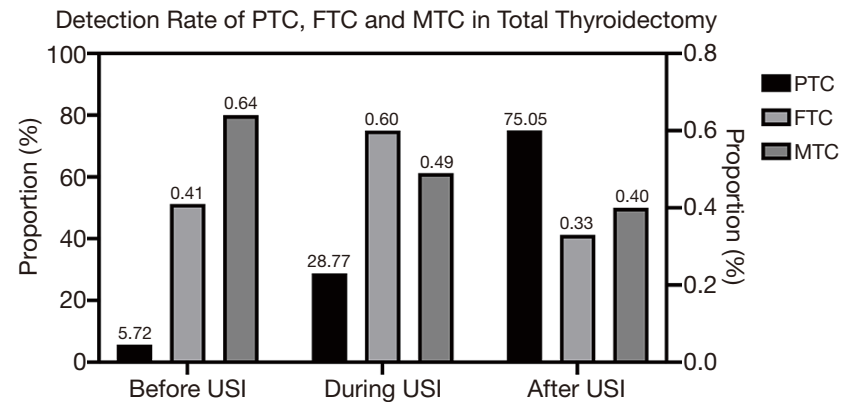

Figure 2 The detection rate of TC subtypes showed that PTC had the highest increasing rate, while FTC and MTC remained relatively stable in three historical periods, "PTC" corresponds to the left-hand ordinate; "FTC" and "MTC" correspond to the right-hand ordinate.

rise occurred in cases of thyroid cancer (Figure $1 A$ ) and the proportion of PTC after 2005 (Figure 1B).

Compared with the period before USI, the detection rate of PTC in all thyroidectomies significantly rose during USI, and was higher even after USI $(75.05 \%$ vs. $28.77 \%$ vs. $\left.5.72 \%, \chi^{2}=8615.92, \mathrm{P}<0.001\right)$. For FTC and medullary thyroid cancer (MTC), the detection rates during the implementation of USI and thereafter, showed no significant difference compared with the period before
USI, except that the detection rate of FTC after USI was significantly lower than during USI $(0.33 \%$ vs. $0.60 \%$, $\left.\chi^{2}=12.243, \mathrm{P}<0.001\right)($ Table 1, Figure 2).

\section{Sex distribution of thyroid cancer in three historical periods}

Overall, female patients outnumbered male patients in the sex distribution of TC throughout three historical periods, except for MTC (Table 2). However, there was a continuous descending trend for the female/male ratio of PTC $\left(\chi^{2}=33.89, \mathrm{P}<0.001\right)$, and a rising trend of female/male ratio for MTC $\left(\chi^{2}=2.56, \mathrm{P}=0.279\right)$. And for the female/male ratio of FTC, there was a process where it first rose and then dropped $\left(\chi^{2}=2.403, \mathrm{P}=0.301\right)$ (Table 2).

\section{Age distribution of thyroid cancer in three historical periods}

The mean age of PTC after USI was slightly lower than during USI $(43.47 \pm 11.02$ vs. $44.28 \pm 12.01, \mathrm{~F}=15.473$, $\mathrm{P}<0.001)$, while the mean age of FTC after USI was much higher than during USI $(51.90 \pm 16.20$ vs. $43.61 \pm 16.40$, $\mathrm{F}=8.844, \mathrm{P}=0.003)$. The mean age distributions of MTC showed no significant difference between historical periods 
Table 2 Sex distribution of thyroid cancer in three different periods

\begin{tabular}{|c|c|c|c|c|c|c|c|c|c|c|}
\hline Histological type & \multicolumn{3}{|c|}{ Before USI } & \multicolumn{3}{|c|}{ During USI } & \multicolumn{3}{|c|}{ After USI } & $\mathrm{P}$ \\
\hline PTC & 99 & 27 & 3.7 & 3,010 & 834 & 3.6 & 9,982 & 3,553 & 2.8 & $<0.001$ \\
\hline FTC & 5 & 4 & 1.3 & 58 & 22 & 2.6 & 37 & 23 & 1.6 & NS \\
\hline MTC & 5 & 9 & 0.6 & 34 & 32 & 1.1 & 42 & 30 & 1.4 & NS \\
\hline
\end{tabular}

PTC, papillary thyroid cancer; FTC, follicular thyroid cancer; MTC, medullary thyroid cancer; USI, universal salt iodization.

Table 3 Mean age distribution of thyroid cancer in three different periods

\begin{tabular}{llll}
\hline Histological type & Before USI & During USI & After USI \\
\hline PTC & $42.92 \pm 12.40$ & $44.28 \pm 12.01^{*}$ & $43.47 \pm 11.02^{*}$ \\
FTC & $39.56 \pm 12.73$ & $43.61 \pm 16.40^{\star *}$ & $51.90 \pm 16.20^{* *}$ \\
MTC & $53.93 \pm 11.95$ & $46.56 \pm 10.10$ & $48.64 \pm 10.83$ \\
\hline
\end{tabular}

${ }^{*}$, statistically significant (after USI vs. during USI, $\mathrm{P}<0.001$ ); **, statistically significant (after USI vs. during USI, $\mathrm{P}<0.01$ ). PTC, papillary thyroid cancer; FTC, follicular thyroid cancer; MTC, medullary thyroid cancer; USI, universal salt iodization.

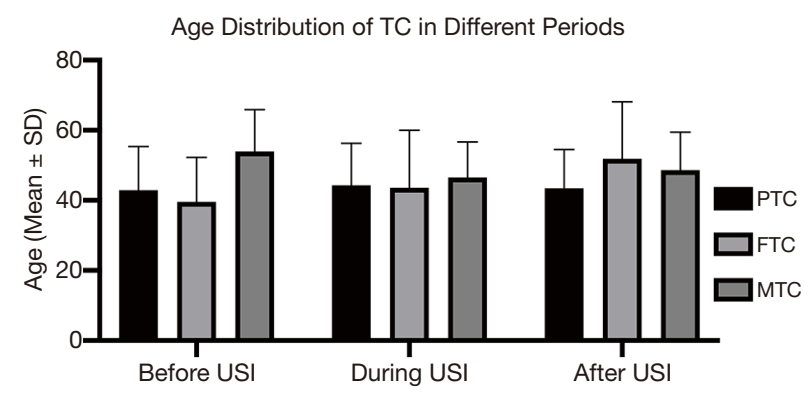

Figure 3 The age distribution of TC subtypes showed an evenly distributed age of PTC, a gradual increase in the age of FTC and a decline-to-rise trend in the age of MTC.

(Table 3, Figure 3). The difference of mean age between two sexes in each TC subtypes did not show significant difference, except that PTC in men were detected in a slightly lower age than women after USI $(42.74 \pm 11.10 \mathrm{vs}$. $43.73 \pm 10.99, \mathrm{P}<0.001)$.

\section{Changing patterns of PTMC in two historical periods}

Papillary thyroid microcarcinoma (PTMC), defined as PTC smaller than $1 \mathrm{~cm}$, was separated as a single type in the category of PTC since 2009 in the database, and we further investigated the changing patterns of PTMC in a 10-year period, from 2009 to 2012 (which is a shorter subsection of the period during USI), and 2013 to 2018 . The detection rate of PTMC in 2013 to 2018 was significantly lower than during 2009 to 2012 (8.64\% vs. $13.99 \%, \mathrm{P}<0.001$ ). PTMC in 2013 to 2018 showed a significantly lower age than in 2009 to $2012(44.88 \pm 10.37$ vs. $46.44 \pm 10.42, \mathrm{P}=0.008)$, and also a lower female/male ratio ( 3.0 vs. $3.8, \chi^{2}=2.64, \mathrm{P}=0.010$ ). The percentage of PTMC coexisting with nodular goiter during 2013 to 2018 was significantly lower than during 2009 to 2012 ( $31 \%$ vs. $41 \%, \chi^{2}=14.529, \mathrm{P}<0.001$ ), while PTMC coexisting with chronic lymphocytic thyroiditis or adenoma did not show significant difference between two periods (Table 4).

\section{Discussion}

In the present study, the detection rate of thyroid cancer increased substantially over a 33-year period, with PTC being the main contributor to the increase of TC. There is a conflicting evidence for iodine as a direct promotor to the increase of PTC. In Switzerland, the proportion of PTC significantly raised among thyroid cancer after iodined salt was introduced as a prophylactic measurement for severe thyroid goiter (17). In Austria, there was a growth in TC as well as the PTC:FTC ratio from 1952 to 1975 after iodized salt was introduced in 1962 (11). However, the steadily increasing rate of PTC was accompanied by a decrease of iodine intake by $50 \%$ in US from 1970 s to 1990 s $(18,19)$. It should be noted, however, that there's a latency period between abrupt changes of iodine intake and subsequent thyroid carcinogenesis, that contemporary changes in iodine intake cannot readily reflect its impact on the pattern of TC. Two studies in China, including inland (20) and coastal (16), consistently described PTC as a manifested subtype of TC a few years after the initiation of USI. In the present study, the increased portion of TC was almost exclusively PTC even after the modulation of USI, 
Table 4 Percentage of PTMC in PTC and percentage of coexisting diseases in PTMC in two periods

\begin{tabular}{lcccccc}
\hline \multirow{2}{*}{ Periods } & \multirow{2}{*}{$\begin{array}{c}\text { Percentage of } \\
\text { PTMC }\end{array}$} & Age, years & F/M & & \multicolumn{2}{c}{ Percentage of coexisting disease } \\
\cline { 6 - 7 } 2009 to 2012 & $13.99 \%$ & $46.44 \pm 10.42$ & 3.8 & $41 \%$ & Chronic lymphocytic thyroiditis & Adenoma \\
2013 to 2018 & $8.64 \%$ & $44.88 \pm 10.37$ & 3.0 & $31 \%$ & $21 \%$ & $2 \%$ \\
$P$ & $<0.001$ & $<0.01$ & NS & $<0.01$ & NS \\
\hline
\end{tabular}

PTC, papillary thyroid cancer; PTMC, papillary thyroid microcarcinoma; USI, universal salt iodization.

which should have passed the latency period or part of the latency period. These domestic studies in China supported a positive correlation between iodine intake and the increasing proportion of PTC. On the other hand, studies have revealed that introduction of iodine could decrease the incidence of FTC while PTC increased $(21,22)$. The increased diagnostic age and lower detection rate of FTC in our study is consistent with these findings, suggesting that iodine is a protective factor for FTC.

The effects of iodine imposed on thyroid carcinogenesis can also be various on the experimental scale. Hamsters can develop papillary and follicular carcinoma when fed with deficient iodine diet (23), or develop enlarged follicles without thyroid tumors when fed with excess iodine (24). When carcinogen $\mathrm{N}$-nitrosomethylurea was added, more thyroid cancer was induced with iodine deficient diet than with iodine sufficient diet in rats (25). In another case, rats did not develop carcinoma with iodine diet ranging from 0.1- to 10-fold normal. But after radiation was added, PTC and FTC developed on both high and low iodine diet while no malignancy was induced under normal iodine supply (26). It turned out, that thyroid carcinoma can be a multifactorial disease, and the effects of iodine can be confounded by chemicals and radiation. These factors should be taken into account when considering the relationship between iodine intake and carcinogenesis.

It was found in rats and mice that deficient iodine diet caused not only DNA modifications but also oxidative stress in thyroid glands (27). And in cell lines of normal thyroid and cancer, iodine and iodolactones induced apoptosis (28). It should be noticed though, that the protective effects of high iodine in these studies were induced in a dose far above the iodine concentration in a human's thyroid, which ranges from $10^{-5}$ to $10^{-6} \mathrm{M}$ (29), or the recommended daily iodine intake in human around 120 to $150 \mu \mathrm{g} / \mathrm{d}$ (30). BRAF mutation is closely related to PTC, and it was found that BRAF mutation was more common in high iodine regions than in normal iodine region (31). Contrary to this observation, a study showed that iodine could abolish BRAF-mediated oncogenesis in thyroid cancer cell lines by blocking a series of microRNA, comparing with notreatment group (32), however, the study did not relate to whether a higher or lower level of iodine would actually have a promoting or suppressing effect for tumor. It is clear that iodine is a critical element for thyroid and exerts peculiar effects on molecular pathways in the pathologensis of thyroid, but it still needs to demonstrate its true effect on carcinogenesis on a diet scale.

It has long been suspected that increasing screening and advancing techniques are accountable for the sharp rise of thyroid cancer, as detailed examinations generate more occult tumors. In the present study, however, FTC and MTC remained relatively stable throughout the period, which indicates that occult finding may not have a major effect on these two subtypes of TC. It was also suggested that smaller PTC, particularly PTMC which is smaller than $1 \mathrm{~cm}$ (33) contributed to the uprise of PTC. Data of autospy in 36 countries showed that in most regions PTMC were actually less frequently seen with high iodine intake, except for Japan, where the incidence rate of PTMC in autopsies was higher with increasing iodine intake (29). The controversial results indicated that although results in autopsy were less likely biased, the incidence rate of microcarcinoma can be confounded by various geographical factors as well as confined by sample sizes. It should be noticed that PTMC, as a "younger" tumor, are more likely to reflect the near effect of iodine intake. In our study, the increase in overall PTC did not happen equally in PTMC. One plausible explanation is that although the diagnostic technology improved, there appeared an increasingly conservative management of PTMC upon chance findings; which will delay surgical treatment in many cases until nodules become larger. Another explanation is that with the descending incidence rate of goiter, PTMC were less likely to be detected in surgeries from benign thyroid diseases. Indeed, there was a descending tendency of goiter 
detected to be coexisting with PTMC, showing a possible prophylactic effect to reduce thyroid goiter after many years of USI.

In general, female outnumbered male in thyroid cancer possibly due to a role of female hormone, particularly estrogen $(34,35)$. However, in our study the male patients of PTC increased more rapidly than female patients. This ratio change is consistent with the observation in Spain, from 4.7 during 1978 to 1985 (mild iodine deficiency) to 3.11 during 1994 to 2001 (iodine sufficiency) (13). It remains inconclusive whether iodine can lead to different incidence rate between sex. One study found iodine stimulated the transcriptional activity of estrogen receptor and increased the expression of several ER regulated genes in breast cancer cells. However, there are currently no straightforward evidence to support whether iodine could affect the ER-related pathways in thyroid cancer (36). A similar dropping F/M ratio was seen in Geneva, Switzerland where there was a significant increase of PTC from 1970-1974 to 1995-1998, with a decrease of female/ male ratio from 4.4 to 2.4 , while the iodine intake did not change $(29,33)$. The author thus attributed the change partly to diagnostic customs but not iodine. More recently in South Korea, another East Asian country where incidence rate of thyroid cancer is high, the female/male ratio in thyroidectomies dropped from 5.63 in 2007 to 4.60 in 2011 (37). In Shenyang, China, the F/M ratio of PTC actually elevated with the increase of iodine (20). The contradictory results suggest that factors other than iodine intake, diagnostic techniques and hormonal secretion should be considered in the changing pattern of female/ male ratio in PTC.

The present study provides some useful information of the trends in TC, for example, an increase of PTC with the popularization of iodine-added salt. However, there are also some limitations in this study. First, it should be noted that biases inevitably exist during a long-time span. Radiation history, diagnostic techniques and changing life styles could all be potential confounders that influenced the results, but many of these variables cannot be properly adjusted for. Second, the time interval between initiation of USI and its effects are uncertain, so the division of periods is totally based on the implementation of USI. More studies and experiments are needed to clarify the relationship between iodine intake and the increased prevalence of thyroid cancer.

\section{Conclusions}

In conclusion, we found that PTC has become the major type in surgery for thyroid cancer, and trends in other histological subtypes remained mostly stable over the periods. We also discovered that the increase in PTC cannot be attributed to the increase of PTMC which is smaller than $1 \mathrm{~cm}$. This trend indicated that contributing factors other than diagnostic activities may play a role in the increase of PTC. Although our results appear to show a relationship between USI and the increase of PTC, the effect of iodine on thyroid cancer is complex from many aspects and still needs to be detailed. This study provides a large dataset regarding the pattern of TC in post-USI era in China, which we believe should provide useful information for the settings of nutrition-related policy in future.

\section{Acknowledgments}

Funding: None.

\section{Footnote}

Reporting Checklist: The authors have completed the STROBE reporting checklist. Available at http://dx.doi. org/10.21037/gs-20-346

Data Sharing Statement: Available at http://dx.doi. org/10.21037/gs-20-346

Peer Review File: Available at http://dx.doi.org/10.21037/gs20-346

Conflicts of Interest: All authors have completed the ICMJE uniform disclosure form (available at http://dx.doi. org/10.21037/gs-20-346). The authors have no conflicts of interest to declare.

Ethical Statement: The authors are accountable for all aspects of the work in ensuring that questions related to the accuracy or integrity of any part of the work are appropriately investigated and resolved. The study was conducted in accordance with the Declaration of Helsinki (as revised in 2013) and approved by the Ethics Committees of Peking Union Medical College Hospital (No. S-K1336). Because all the parameters were routinely obtained at 
the time of the study and no additional investigations or procedures were carried out, informed consent was not required.

Open Access Statement: This is an Open Access article distributed in accordance with the Creative Commons Attribution-NonCommercial-NoDerivs 4.0 International License (CC BY-NC-ND 4.0), which permits the noncommercial replication and distribution of the article with the strict proviso that no changes or edits are made and the original work is properly cited (including links to both the formal publication through the relevant DOI and the license). See: https://creativecommons.org/licenses/by-nc-nd/4.0/.

\section{References}

1. Pearce A, Bradley C, Hanly P, et al. Projecting productivity losses for cancer-related mortality 2011 - 2030. BMC Cancer 2016;16:804.

2. Sun KX, Zheng RS, Zhang SW, et al. Reports of Cancer Incidence and Mortality in Different Areas of China, 2015. China Cancer 2019;28:1-11.

3. Wang J, Yu F, Shang Y, et al. Thyroid cancer: incidence and mortality trends in China, 2005-2015. Endocrine 2020;68:163-73.

4. Sinnott B, Ron E, Schneider AB. Exposing the thyroid to radiation: a review of its current extent, risks, and implications. Endocr Rev 2010;31:756-73.

5. Schmid D, Ricci C, Behrens G, et al. Adiposity and risk of thyroid cancer: a systematic review and meta-analysis. Obes Rev 2015;16:1042-54.

6. Marcello MA, Cunha LL, Batista FA, et al. Obesity and thyroid cancer. Endocr Relat Cancer 2014;21:T255-71.

7. Zhu C, Zheng T, Kilfoy BA, et al. A birth cohort analysis of the incidence of papillary thyroid cancer in the United States, 1973-2004. Thyroid 2009;19:1061-6.

8. Camargo RY, Tomimori EK, Neves SC, et al. Thyroid and the environment: exposure to excessive nutritional iodine increases the prevalence of thyroid disorders in Sao Paulo, Brazil. Eur J Endocrinol 2008;159:293-9.

9. Zimmermann MB, Boelaert K. Iodine deficiency and thyroid disorders. Lancet Diabetes Endocrinol 2015;3:286-95.

10. Global scorecard of iodine nutrition in 2019. Available online: https://www.ign.org/cm_data/Global_ Scorecard_2019_SAC.pdf

11. Hofstädter F. Frequency and morphology of malignant tumours of the thyroid before and after the introduction of iodine-prophylaxis. Virchows Arch A Pathol Anat Histol 1980;385:263-70.

12. Radespiel-Tröger M, Batzler WU, Holleczek B, et al. Rising incidence of papillary thyroid carcinoma in Germany. Bundesgesundheitsblatt Gesundheitsforschung Gesundheitsschutz 2014;57:84-92.

13. Rego-Iraeta A, Perez-Mendez LF, Mantinan B, et al. Time trends for thyroid cancer in northwestern Spain: true rise in the incidence of micro and larger forms of papillary thyroid carcinoma. Thyroid 2009;19:333-40.

14. Harach HR, Ceballos GA. Thyroid cancer, thyroiditis and dietary iodine: a review based on the Salta, Argentina model. Endocr Pathol 2008;19:209-20.

15. Yang L, Sun TT, Yuan YN, et al. Time trends and pathological characteristics of thyroid cancer in urban Beijing, 1995 - 2010. Zhonghua Yu Fang Yi Xue Za Zhi 2013;47:109-12.

16. Wang $Y$, Wang W. Increasing incidence of thyroid cancer in Shanghai, China, 1983-2007. Asia Pac J Public Health 2015;27:NP223-9.

17. Bubenhofer R, Hedinger C. Thyroid neoplasms before and after the prophylactic supplementation of table salt with iodine. Schweiz Med Wochenschr 1977;107:733-41.

18. Horn-Ross PL, Lichtensztajn DY, Clarke CA, et al. Continued rapid increase in thyroid cancer incidence in California: trends by patient, tumor, and neighborhood characteristics. Cancer Epidemiol Biomarkers Prev 2014;23:1067-79.

19. Hollowell JG, Staehling NW, Hannon WH, et al. Iodine nutrition in the United States. Trends and public health implications: iodine excretion data from National Health and Nutrition Examination Surveys I and III (1971-1974 and 1988-1994). J Clin Endocrinol Metab 1998;83:3401-8.

20. Dong $\mathrm{W}$, Zhang $\mathrm{H}$, Zhang $\mathrm{P}$, et al. The changing incidence of thyroid carcinoma in Shenyang, China before and after universal salt iodization. Med Sci Monit 2013;19:49-53.

21. Pettersson B, Adami HO, Wilander E, et al. Trends in thyroid cancer incidence in Sweden, 1958-1981, by histopathologic type. Int J Cancer 1991;48:28-33.

22. Harach HR, Escalante DA, Onativia A, et al. Thyroid carcinoma and thyroiditis in an endemic goitre region before and after iodine prophylaxis. Acta Endocrinol (Copenh) 1985;108:55-60.

23. Fortner JG, George PA, Sternberg SS. The development of thyroid cancer and other abnormalities in Syrian hamsters maintained on an iodine deficient diet. Surg Forum 1958;9:646-50.

24. Correa P, Welsh RA. The effect of excessive iodine intake on 
the thyroid gland of the rat. Arch Pathol 1960;70:247-51.

25. Ohshima M, Ward JM. Promotion of N-methyl-Nnitrosourea-induced thyroid tumors by iodine deficiency in F344/NCr rats. J Natl Cancer Inst 1984;73:289-96.

26. Boltze C, Brabant G, Dralle H, et al. Radiation-induced thyroid carcinogenesis as a function of time and dietary iodine supply: an in vivo model of tumorigenesis in the rat. Endocrinology 2002;143:2584-92.

27. Maier J, van Steeg H, van Oostrom C, et al. Iodine deficiency activates antioxidant genes and causes DNA damage in the thyroid gland of rats and mice. Biochim Biophys Acta 2007;1773:990-9.

28. Gärtner R, Rank P, Ander B. The role of iodine and deltaiodolactone in growth and apoptosis of malignant thyroid epithelial cells and breast cancer cells. Hormones (Athens) 2010;9:60-6.

29. Zimmermann MB, Galetti V. Iodine intake as a risk factor for thyroid cancer: a comprehensive review of animal and human studies. Thyroid Res 2015;8:8.

30. Wu L, Yu J, Kang W, et al. Iodine Nutrition and Thyroid Diseases. Zhongguo Yi Xue Ke Xue Yuan Xue Bao 2013;35:363-8.

31. Guan H, Ji M, Bao R, et al. Association of high iodine

Cite this article as: Zeng Z, Li K, Kang W, Yu J, Wang X, Zhang Z, Sun J, Ouyang S. Changing patterns of thyroid cancer in different stages of Universal Salt Iodization in Peking Union Medical College Hospital, 1986-2018. Gland Surg 2020;9(5):13381345. doi: $10.21037 /$ gs-20-346 intake with the T1799A BRAF mutation in papillary thyroid cancer. J Clin Endocrinol Metab 2009;94:1612-7.

32. Fuziwara CS, Kimura ET. High iodine blocks a Notch/ miR-19 loop activated by the BRAF(V600E) oncoprotein and restores the response to TGFbeta in thyroid follicular cells. Thyroid 2014;24:453-62.

33. Verkooijen HM, Fioretta G, Pache JC, et al. Diagnostic changes as a reason for the increase in papillary thyroid cancer incidence in Geneva, Switzerland. Cancer Causes Control 2003;14:13-7.

34. Zabuliene L, Jasilionis D, Miseikyte-Kaubriene E, et al. Parity and Risk of Thyroid Cancer: a Population-Based Study in Lithuania. Horm Cancer 2017;8:325-9.

35. Zane M, Parello C, Pennelli G, et al. Estrogen and thyroid cancer is a stem affair: A preliminary study. Biomed Pharmacother 2017;85:399-411.

36. He S, Wang B, Lu X, et al. Iodine stimulates estrogen receptor singling and its systemic level is increased in surgical patients due to topical absorption. Oncotarget 2017;9:375-84.

37. Sung MW, Park B, An SY, et al. Increasing thyroid cancer rate and the extent of thyroid surgery in Korea. PLoS One 2014;9:e113464. 